\title{
Strain Typing of Trichosporon asahii Clinical Isolates by Random Amplification of Polymorphic DNA (RAPD) Analysis
}

\author{
Thayanidhi Premamalini ${ }^{1}$ Vijayaraman Rajyoganandh ${ }^{2}$ Ramaraj Vijayakumar ${ }^{1}$ \\ Hemanth Veena ${ }^{1}$ Anupma Jyoti Kindo ${ }^{1}$ Rungmei SK Marak ${ }^{3}$
}

${ }^{1}$ Department of Microbiology, Sri Ramachandra Medical College \& Research Institute, SRIHER, Porur, Chennai, Tamil Nadu, India

${ }^{2}$ Department of Microbiology, Vels Institute of Science, Technology and Advanced Studies, Vels Institute, Chennai, Tamil Nadu, India

${ }^{3}$ Department of Microbiology, Sanjay Gandhi Post Graduate Institute of Medical Sciences, Lucknow, Uttar Pradesh, India

\author{
Address for correspondence Thayanidhi Premamalini MBBS, \\ $\mathrm{MD}, \mathrm{PhD}$, Associate professor, Department of Microbiology, Sri \\ Ramachandra Medical College \& Research Institute, SRIHER, Porur, \\ Chennai 600116, Tamil Nadu, India \\ (e-mail:drtpremamalini@gmail.com).
}

\begin{abstract}
Keywords

- strain typing

- Trichosporon asahii

- genetic diversity

- RAPD

Objective The aim of this study was to identify and isolate Trichosporon asahii (T. asahii) from clinical samples and to assess the genetic relatedness of the most frequently isolated strains of $T$. asahii using random amplification of polymorphic DNA (RAPD) primers GAC-1 and M13.

Methods All the clinical samples that grew Trichosporon species, identified and confirmed by polymerase chain reaction (PCR) using Trichosporon genus-specific primers, were considered for the study. Confirmation of the species $T$. asahii was carried out by T. asahii-specific PCR. Fingerprinting of the most frequently isolated T. asahii isolates was carried out by RAPD using random primers GAC- 1 and M13.

Results Among the 72 clinical isolates of Trichosporon sp. confirmed by Trichosporon-specific PCR, 65 were found to be T. asahii as identified by T. asahii-specific PCR. Fingerprinting of the 65 isolates confirmed as T. asahii using GAC-1 RAPD primer yielded 11 different patterns, whereas that of M13 primer produced only 5 patterns. The pattern I was found to be the most predominant type (29.2\%) followed by pattern III (16.9\%) by GAC- 1 primer.

Conclusions This study being the first of its kind in India on strain typing of $T$. asahii isolates by adopting RAPD analysis throws light on genetic diversity among the $T$. asahii isolates from clinical samples. Fingerprinting by RAPD primer GAC-1 identified more heterogeneity among the T. asahii isolates than M13.
\end{abstract}

\section{Introduction}

Trichosporon spp. is emerging yeast that is extensively distributed in nature. They form a part of the normal human flora of the mucosal and cutaneous surfaces of humans. ${ }^{1}$ The infections caused by Trichosporon spp. in humans can be superficial, mucosa-associated, or deep-seated infections,

published online

July 3, 2021
DOI https://doi.org/ $10.1055 / \mathrm{s}-0041-1731111$ ISSN 0974-2727 and are collectively described as "Trichosporonosis."2 In immunocompetent healthy individuals, Trichosporon spp. may cause superficial infections like white piedra or skin infections. However, in severely immunocompromised patients such as hematological malignancy patients and solid organ transplant recipients, Trichosporon spp. can cause invasive infections., ${ }^{3,4}$ Trichosporonosis is frequently (c) 2021. The Indian Association of Laboratory Physicians.

This is an open access article published by Thieme under the terms of the Creative Commons Attribution-NonDerivative-NonCommercial-License, permitting copying and reproduction so long as the original work is given appropriate credit. Contents may not be used for commercial purposes, or adapted, remixed, transformed or built upon. (https://creativecommons.org/licenses/by-nc-nd/4.0/).

Thieme Medical and Scientific Publishers Pvt. Ltd. A-12, 2nd Floor, Sector 2, Noida-201301 UP, India 
associated with resistance to 5-fluorocytosine, fluconazole, and amphotericin B. Also, echinocandins have little or no activity against Trichosporon spp. Hence, these infections are usually difficult to treat and are associated with high morbidity and mortality rate. ${ }^{5}$ The therapies are only effective if the disease is detected at an initial stage, and, therefore, early diagnosis plays an important role in the successful management of patients with disseminated trichosporonosis. Unfortunately, difficulties in the identification of Tichosporon spp. may lead to delay in starting the patient on correct treatment.6,7 DNA-based methods have been extensively used for the accurate identification of Trichosporon spp. ${ }^{8}$ In this regard, ribosomal genes represent particularly consistent evaluative markers and include alternating conserved regions (D1/D2 region of the 28S rDNA) and variable regions (ITS and IGS1 regions) that may be useful for species identification and phylogenetic studies. ${ }^{9-11}$ In 1998, Sugita et al designed primers that would specifically amplify only T. asahii based on the internal transcribed spacer regions of this organism's genome. Amplification products were selectively obtained from only T. asahii DNA; the DNAs of other Trichosporon species as well as those of other medically relevant yeasts were not amplified. ${ }^{10,12}$

There are about 51 species of Trichosporon that have been identified worldwide so far, among which 16 species are of clinical relevance. ${ }^{13}$ Currently, T. asahii is the most frequent reported pathogenic yeast in the genus Trichosporon, from patients with superficial and invasive trichosporonosis. ${ }^{14-17}$

Species identification and molecular typing have become critical elements of nosocomial fungal outbreak investigations. These studies reveal the possible source of nosocomial infection, genetic comparison between invasive or noninvasive isolates, and comparison of the genotypes. ${ }^{18}$ Genotyping of an infectious agent is usually performed for assessing the genetic relatedness of the strains, especially for epidemiological purposes. Although there are many molecular methods for genotyping Candida and Cryptococcus species, only a few methods are used for typing Trichosporon spp. These methods include random amplification of polymorphic DNA (RAPD), restriction fragment length polymorphism, amplified fragment length polymorphism, gene sequencing, and glucuronoxylomannan polysaccharide antigen analysis. ${ }^{19-24}$

To the best of our knowledge, no data on strain typing and genetic diversity of Trichosporon sp. have been reported in India. Hence, in the current study, we report on the isolation of $T$. asahii from various clinical samples and evaluation of the genetic relatedness of these strains by RAPD analysis with GAC-1 and M13 primers.

\section{Materials and Methods}

Study design: Hospital-based descriptive study.

Sample collection and study period: Isolates recovered from clinical samples from medical centers across India, over a period of 5 years (July 2011-June 2016), were considered for the study. Out of the total 72 Trichosporon isolates that were processed in our study, 55 were from South India and the remaining were 17 from North India.

Sample source: Out of the 72 isolates from clinical samples, 43 isolates (59.7\%) were from urine. Twelve (16.7\%) isolates were from blood. Seven isolates (9.7\%) grew from samples collected immediately after insertion of percutaneous nephrostomy (PCN) tube. Out of the five $(6.9 \%)$ respiratory isolates, three were from sputum and two from bronchoalveolar lavage. Four (5.6\%) of the Trichosporon sp. were isolated from pus, and one isolate (1.4\%) grew from peritoneal dialysis (PD) fluid collected from the dialysis bag of a patient who underwent PD.

\section{Phenotypic Characterization}

The isolates, which produced dry yeast like colonies on Sabouraud dextrose agar plate, were further characterized by performing gram stain, Dalmau technique, and urea hydrolysis. Urease-positive isolates that showed the presence of blastoconidia, pseudohyphae, and arthroconidia were provisionally identified as belonging to the genus Trichosporon.

\section{Preservation of Culture}

The cultures were preserved at $-20^{\circ} \mathrm{C}$ on skimmed milk medium until use. ${ }^{25}$

\section{Genotypic Characterization}

For identification of Trichosporon isolates to species level (i.e., T. asahii) and strain typing, three different polymerase chain reactions (PCRs) were performed with three sets of primers.

\section{DNA Extraction}

Genomic DNA from clinical isolates, reference strains of Trichosporon species, and Candida species (Trichosporon reference strains were procured from Microbial Type Culture Collection and Gene Bank [MTCC], India-T. asahii MTCC 6179, T. asteroides MTCC 7632, T. cutaneum var. cutaneum MTCC 1963, and T. jirovecii MTCC 9036; Candida reference strains were from American Type Culture Collection [ATCC]-Candida albicans ATCC 90028) were isolated by the method of Mirhendi et al and Vijayakumar et al. Briefly, the culture was suspended in $400 \mu \mathrm{L}$ TES (2-[Tris(hydroxymethyl) methylamino]-1-ethane sulfonic acid) lysis buffer (10 mM TRIS [tris(hydroxymethyl)aminomethane] [pH-8], 1 mM EDTA [Ethylenediamine tetraacetic acid] [pH8], $3 \%$ SDS [Sodium Dodecyl Sulfate], and $100 \mathrm{mM} \mathrm{NaCl}$ ) in a microcentrifuge tube and boiled for 1 minute. About $400 \mu \mathrm{L}$ of phenol:chloroform (1:1) mixture was added, vortexed, and centrifuged at $10,000 \mathrm{rpm}$ for 10 minutes. The aqueous layer was transferred to a fresh microcentrifuge tube and an equal volume of chloroform was added, vortexed, and centrifuged at 10,000 rpm for 10 minutes. The aqueous layer was transferred to another fresh microcentrifuge tube. DNA was precipitated by adding equal volume of ice-cold isopropyl alcohol and washed twice with $70 \%$ ethanol. The pellet was dissolved in $40 \mu \mathrm{L}$ sterile nuclease-free water and stored at $-20^{\circ} \mathrm{C}$ until use. ${ }^{26,27}$ 


\section{PCR-Based Identification of Trichosporon Species}

All the 72 clinical isolates and reference strains were initially subjected to Trichosporon specific PCR. This confirmed the identity of all the isolates identified as Trichosporon phenotypically, following which T. asahii-specific PCR was performed for all the clinical isolates, which identified only $T$. asahii.

\section{Trichosporon-Specific PCR}

The first set of primers used were Trichosporon genus-specific primers (TRF [forward]-5'AGAGGCCTACCATGGTATCA 3' TRR [reverse]-5'TAAGACCCAATAGAGCCCTA 3'). They would specifically amplify only Trichosporon species, by aligning with the small subunit of ribosomal DNA sequences. This region is not conserved in other medically important yeasts and hence were not amplified. ${ }^{10}$ Trichosporon-specific PCR was done by adopting the reaction conditions standardized in our laboratory. ${ }^{28}$

\section{Trichosporon asahii-Specific PCR}

The second sets of primers were $T$. asahii-specific primers (TASF [forward]-5'GGATCATTAGTGATTGC CTTTATA3' TASR [reverse]-5'AGCACGCTTCAACACAATGGAC3') that identified all the T. asahii. The species specificity of the primers was confirmed by previous studies through BLAST search. ${ }^{29}$ The PCR master mix was prepared containing $25 \mu \mathrm{L}$ of PCR mix (Takara, Japan), $1 \mu \mathrm{L}$ of forward (TASF) and reverse primer each (TASR) (GeNei, Bangalore), $1 \mu \mathrm{L}$ of template DNA, and the volume made up to $50 \mu \mathrm{L}$ with sterile nuclease-free water. The reaction mixtures were amplified in a thermal cycler (Veriti 96 well, Applied Biosystems, United States), with minor modifications of the PCR reactions conditions ( - Table 1), described earlier by Sugita et al, in 1998. ${ }^{12}$ The amplified product was electrophoresed on $1.5 \%$ (wt/vol) agarose gel, stained with ethidium bromide, and visualized with UV light.

\section{Fingerprinting by RAPD Analysis}

DNA fingerprinting of $T$. asahii isolates was carried out by RAPD analysis, usingrandomprimers, GAC-1 (5'-GACGACGACGAC-3') and M13 (5'- GAGGGTGGCGGTTCT-3') separately. ${ }^{22,30}$ Both these RAPD primers were optimized separately. ${ }^{22,31}$ The PCR master mix was prepared containing $25 \mu \mathrm{L}$ of PCR mix (Takara, Japan), $1 \mu \mathrm{L}$ of GAC-1 or M13 primer (GeNei, Bangalore), $3 \mu \mathrm{L}$ of template DNA, and the volume made up to $30 \mu \mathrm{L}$ with sterile nuclease-free water. The PCR reaction conditions are shown in - Table 1. Amplified products were separated by $1.5 \%$ (wt/vol) agarose gel electrophoresis and similarities and differences among DNA fragment banding patterns were visualized and recorded. ${ }^{31}$

\section{Results}

\section{Genotypic Characterization Trichosporon-Specific PCR}

PCR was performed initially with Trichosporon genus-specific primers to double check for accurate identification of this genus. This pair of primer confirmed that all the 72 phenotypically identified isolates belonged to the genus Trichosporon..$^{28}$

\section{Trichosporon asahii-Specific PCR}

PCR amplification of genomic DNA with T. asahii-specific primers resulted in specific amplification of a single DNA fragment at approximately 430bp from 65 clinical Trichosporon isolates only, while the remaining seven isolates did not yield an amplified product. T. asahii MTCC 6179 also produced band at approximately 430bp (positive control), whereas T. jirovecii MTCC 9036 did not yield an amplification product of the DNA isolated (negative control) ( - Fig. 1).

\section{Fingerprinting by RAPD}

\section{RAPD Genotypes by GAC-1 and Sample Source}

Fingerprinting of the 65 isolates confirmed as T. asahii strains using GAC-1 RAPD primer yielded 11 different patterns, which were arbitrarily referred to as I to XI (-Fig. 2). The pattern I was found to be the most predominant type in 19/65 (29.2\%) isolates, followed by pattern III in 11/65 (16.9\%) isolates. Pattern $X$ was the third common pattern found in 9/65 (13.8\%) of the isolates. The distributions of the other patterns are shown in - Table 2. It was observed in our study that the pattern I was the predominant pattern among the urinary isolates $13 / 38$ (34.2\%) and pattern X was the most predominant pattern among the blood 3/11 (27.3\%), PCN 4/7 (57.1\%), and PD fluid isolate $1 / 1$ (100\%) (-Table 2). The 17 samples from North India produced patterns (pattern IX-5/17, pattern $\mathrm{X}-9 / 17$, and pattern $\mathrm{XI}-3 / 17$ ) that were different from those produced by the isolates from South India (patterns I-VIII).

Table 1 PCR reaction conditions for identification of Trichosporon asahii and its RAPD fingerprinting

\begin{tabular}{|l|l|l|l|l|l|l|}
\hline \multirow{2}{*}{ Reaction } & \multicolumn{2}{|l|}{ T. asahii-specific } & \multicolumn{2}{c|}{$\begin{array}{c}\text { RAPD } \\
\text { GAC-1 }\end{array}$} \\
\cline { 2 - 7 } & Temp & Time & Temp & Time & Temp & Time \\
\hline Initial denaturation & $95^{\circ} \mathrm{C}$ & $7 \mathrm{~min}$ & $95^{\circ} \mathrm{C}$ & $10 \mathrm{~min}$ & $95^{\circ} \mathrm{C}$ & $10 \mathrm{~min}$ \\
\hline Denaturation & $95^{\circ} \mathrm{C}$ & $30 \mathrm{~s}$ & $95^{\circ} \mathrm{C}$ & $30 \mathrm{~s}$ & $95^{\circ} \mathrm{C}$ & $30 \mathrm{~s}$ \\
\hline Annealing & $56^{\circ} \mathrm{C}$ & $30 \mathrm{~s}$ & $45^{\circ} \mathrm{C}$ & $30 \mathrm{~s}$ & $40^{\circ} \mathrm{C}$ & $30 \mathrm{~s}$ \\
\hline Extension & $72^{\circ} \mathrm{C}$ & $30 \mathrm{~s}$ & $72^{\circ} \mathrm{C}$ & $2.5 \mathrm{~min}$ & $72^{\circ} \mathrm{C}$ & $2.5 \mathrm{~min}$ \\
\hline Final extension & $72^{\circ} \mathrm{C}$ & $10 \mathrm{~min}$ & $72^{\circ} \mathrm{C}$ & $10 \mathrm{~min}$ & $72^{\circ} \mathrm{C}$ & $10 \mathrm{~min}$ \\
\hline
\end{tabular}

Abbreviations: PCR, polymerase chain reaction; RAPD, random amplification of polymorphic DNA. 


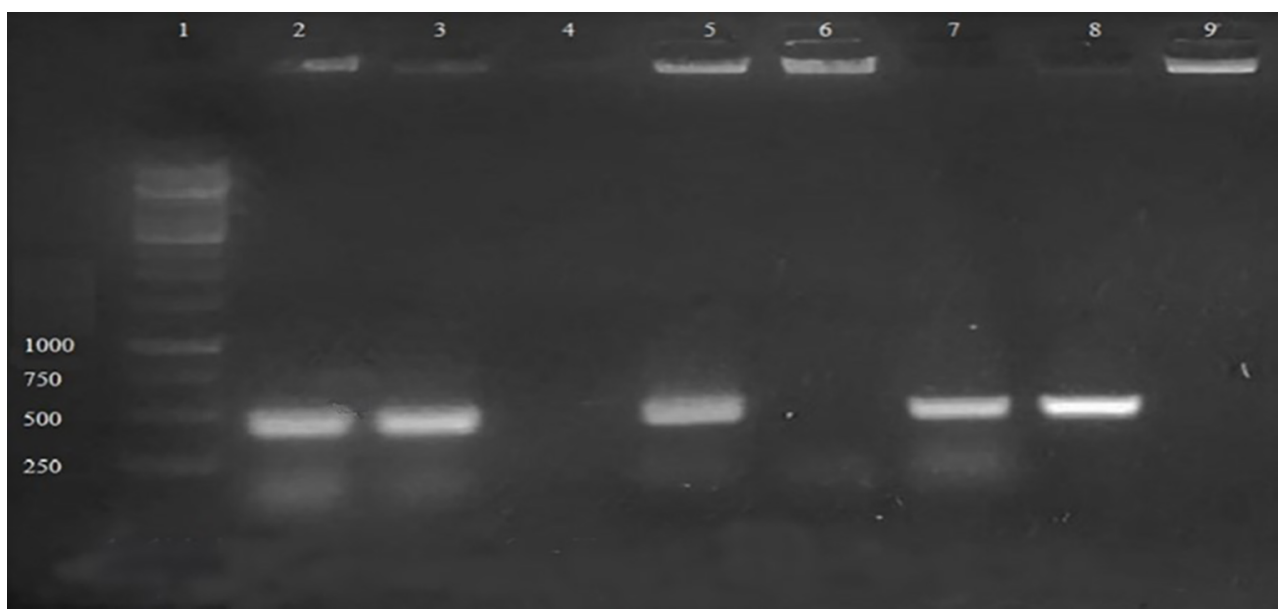

Fig. 1 Trichosporon asahii-specific PCR:Lane 1-1kb ladder; Lane 2-T. asahii MTCC 6179;Lanes 3, 4, 5, 6, 7, 8-clinical isolates; Lane 9-T. jirovecii MTCC 9036

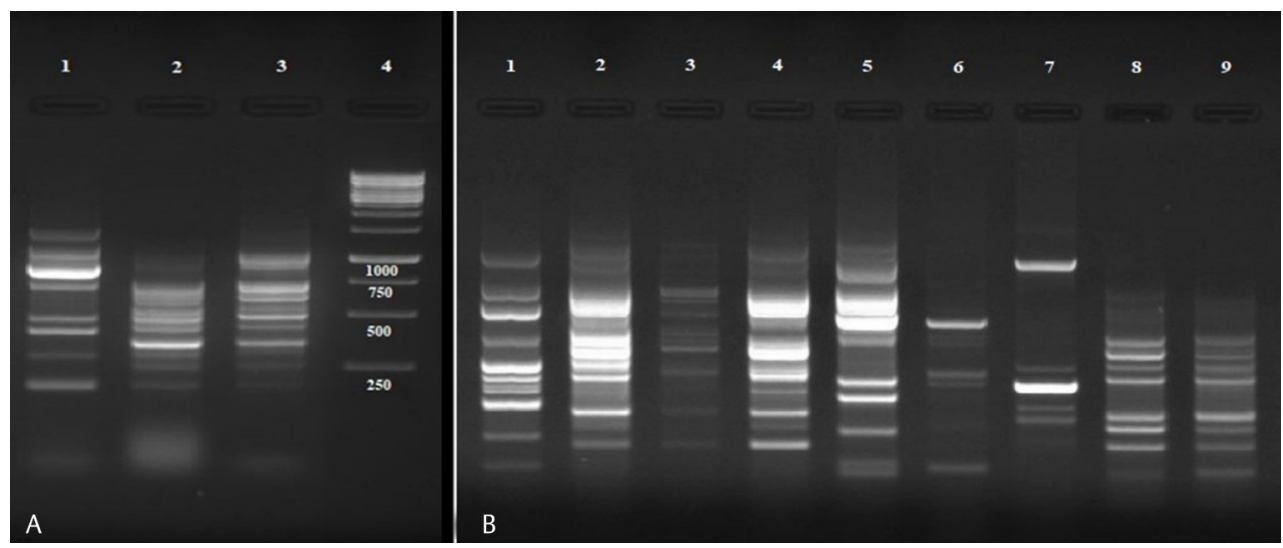

Fig. 2 Fingerprinting by RAPD-GAC-1:Lane A1-pattern IX; Lane A2-pattern XI; Lane A3-pattern X; Lane 4-1 kb ladder.Lane B1-pattern VIII; Lane 2-pattern VII; Lane B3-pattern VI; Lane 4-pattern V; Lane B5-pattern IV; Lane 6-pattern III; Lane B7-pattern II; Lane 8, 9, 10-pattern I.

Table 2 RAPD genotypes by GAC-1 and sample source

\begin{tabular}{|c|c|c|c|c|c|c|}
\hline $\begin{array}{l}\text { Genotypes } \\
n=65\end{array}$ & $\begin{array}{l}\text { Urine } \\
n=38\end{array}$ & $\begin{array}{l}\text { PCN } \\
n=7\end{array}$ & $\begin{array}{l}\text { Blood } \\
n=11\end{array}$ & $\begin{array}{l}\text { Respiratory } \\
n=5\end{array}$ & $\begin{array}{l}\text { Pus/wound } \\
\text { swab } \\
n=3\end{array}$ & $\begin{array}{l}\text { PD fluid } \\
n=1\end{array}$ \\
\hline I-19 (29.2\%) & $13(34.2 \%)$ & 0 & $2(18.2 \%)$ & $2(40 \%)$ & $2(66.7 \%)$ & 0 \\
\hline II-3 (4.6\%) & $2(5.3 \%)$ & 0 & 1 (9.1\%) & 0 & 0 & 0 \\
\hline III-11 (16.9\%) & $7(18.4 \%)$ & 0 & $2(18.2 \%)$ & 1 (20\%) & $1(33.3 \%)$ & 0 \\
\hline IV-3 (4.6\%) & $3(7.9 \%)$ & 0 & 0 & 0 & 0 & 0 \\
\hline V-5 (7.7\%) & $4(10.5 \%)$ & 0 & 1 (9.1\%) & 0 & 0 & 0 \\
\hline VI-2 (3.1\%) & $2(5.3 \%)$ & 0 & 0 & 0 & 0 & 0 \\
\hline VII-3 (4.6\%) & $3(7.9 \%)$ & 0 & 0 & 0 & 0 & 0 \\
\hline VIII-2 (3.1\%) & $2(5.3 \%)$ & 0 & 0 & 0 & 0 & 0 \\
\hline IX-5 (7.7\%) & $1(2.6 \%)$ & $2(28.6 \%)$ & $1(9.1 \%)$ & 1 (20\%) & 0 & 0 \\
\hline X-9 (13.8\%) & 0 & $4(57.1 \%)$ & $3(27.3 \%)$ & 1 (20\%) & 0 & $1(100 \%)$ \\
\hline $\mathrm{XI}-3(4.6 \%)$ & $1(2.6 \%)$ & $1(14.3 \%)$ & 1 (9.1\%) & 0 & 0 & 0 \\
\hline
\end{tabular}

Abbreviations: PCN, percutaneous nephrostomy; PD, peritoneal dialysis; RAPD, random amplification of polymorphic DNA.

There was also an interesting finding that there was a regional variation in the pattern from North India and South India. The pattern from North was predominantly $\mathrm{X}$, whereas the pattern from South was predominantly I and III.

\section{RAPD Genotypes by M13 and Sample Source}

RAPD analysis of the 65 isolates using M13 yielded only five patterns I to V ( - Fig. 3). Pattern II was the most common one, that is, $25 / 65$ (38.5\%). The next common pattern 


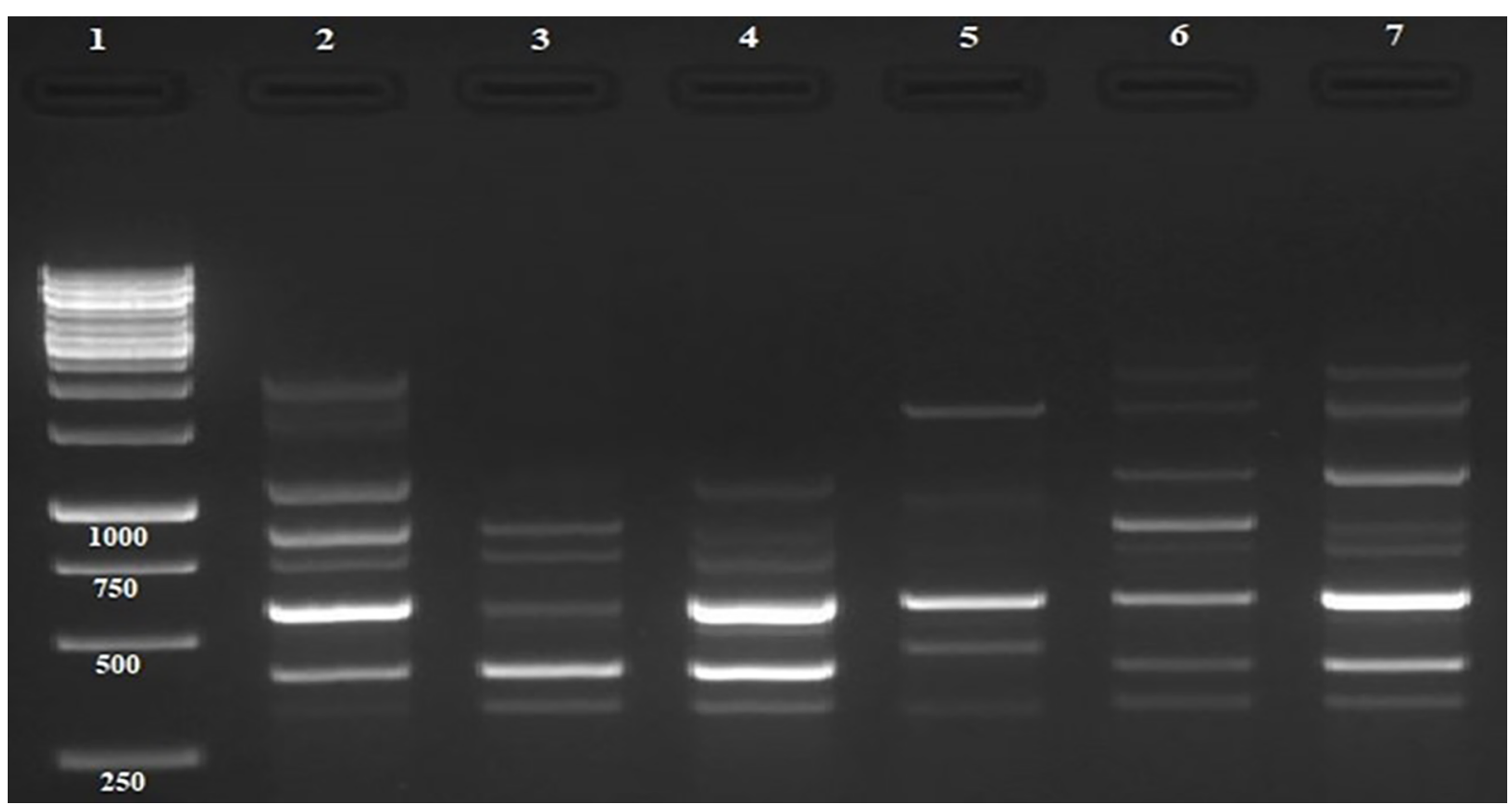

Fig. 3 Fingerprinting by RAPD-M13:Lane 1-kb ladder; Lane 2-pattern V; Lane 3-pattern IV; Lane 4-pattern III; Lane 5-pattern I; Lanes 6, 7-pattern II.

Table 3 RAPD genotypes by M13 and sample source

\begin{tabular}{|l|l|l|l|l|l|l|}
\hline $\begin{array}{l}\text { Genotypes } \\
\boldsymbol{n}=65\end{array}$ & $\begin{array}{l}\text { Urine } \\
\boldsymbol{n}=38\end{array}$ & $\begin{array}{l}\text { PCN } \\
\boldsymbol{n}=\mathbf{7}\end{array}$ & $\begin{array}{l}\text { Blood } \\
\boldsymbol{n}=11\end{array}$ & $\begin{array}{l}\text { Respiratory } \\
\boldsymbol{n}=5\end{array}$ & $\begin{array}{l}\text { Pus/wound } \\
\boldsymbol{n}=3\end{array}$ & $\begin{array}{l}\text { PD fluid } \\
\boldsymbol{n}=\mathbf{1}\end{array}$ \\
\hline I-15(23\%) & $9(23.7 \%)$ & 0 & $4(36.4 \%)$ & $1(20 \%)$ & $1(33.3 \%)$ & 0 \\
\hline II-25(38.5\%) & $19(50 \%)$ & $1(14.3 \%)$ & $1(9.1 \%)$ & $2(40 \%)$ & $2(66.7 \%)$ & 0 \\
\hline III-9 (13.8\%) & $7(18.4 \%)$ & 0 & $2(18.2 \%)$ & 0 & 0 & 0 \\
\hline IV-8 (12.3\%) & $1(2.6 \%)$ & $3(42.9 \%)$ & $3(27.3 \%)$ & 0 & 0 & $1(100 \%)$ \\
\hline V-8 (12.3\%) & $2(5.3 \%)$ & $3(42.9 \%)$ & $1(9.1 \%)$ & $2(40 \%)$ & 0 & 0 \\
\hline
\end{tabular}

Abbreviations: PCN, percutaneous nephrostomy; PD, peritoneal dialysis; RAPD, random amplification of polymorphic DNA.

was pattern I in 15/65 (23\%) of the isolates. Pattern II was common among urine 19/38 (50\%) and pus/wound swab isolates $2 / 3$ (66.7\%), and pattern I was common among blood isolates $4 / 11$ (36.4\%). Among PCN isolates, the most common were pattern IV and pattern $\mathrm{V}$. The distribution of other patterns among the isolates is shown in - Table 3. The isolates from North India produced predominantly different patterns (pattern IV-8/17, pattern V-8/17) compared to those produced from the isolates from South India (patterns I, II, and III), whereas one PCN isolate from North India produced pattern II that was commonly seen in isolates from South India.

\section{Discussion}

Trichosporon sp. being the third most common cause of disseminated yeast infections in humans is usually difficult to diagnose, does not respond to treatment with routinely used antifungal agents, and is associated with high mortality rates. ${ }^{32}$ Among the Trichosporon sp., T. asahii is the most common etiological agent causing trichosporonosis, in immunocompromised as well as immunocompetent patients. Early diagnosis and treatment are therefore of utmost importance in trichosporonosis patients. ${ }^{33}$
The identification of this genus by phenotypic methods is usually time-consuming and inadequate to identify Trichosporon spp. ${ }^{34,35}$ Also, commercially available automated methods based on the assimilation of carbon and nitrogen compounds for identification may result in misidentification of the isolates and hence have to be supplemented with molecular methods. Molecular investigations such as PCR with species-specific primers have been developed with the purpose of applying a more simple, specific, and rapid method for mycological diagnosis of Trichosporon sp. ${ }^{23,34}$ The main advantages of these techniques are their high sensitivity and specificity, and at the same time being fully discriminative even for closely related species.

In our study, all the 72 isolates were confirmed as belonging to genus Trichosporon using Trichosporon-specific PCR, which is a rapid PCR-based molecular method. The primers TRF and TRR were chosen to align with the genus Trichosporon. Sugita et al had earlier sequenced the ITS region and described this approach for detection of all species of the emerging yeast, Trichosporon. ${ }^{10}$ The data from the previous studies also indicate that the PCR detection system is useful for identifying these yeasts. ${ }^{12}$ Among these 72 Trichosporon isolates, 65 were identified as T. asahii by Trichosporon 
asahii-specific PCR using TASF and TASR primers. The TASF primer is specific for $T$. asahii and has been described previously by Sugita et al, ${ }^{11,12}$ while the sequence of our TASR primer that matched the sequence from five Trichosporon species (T. asahii, Trichosporon asteroides, Trichosporon japonicum, Trichosporon ovoides, and Trichosporon aquatile) was used by Ahmad et al. ${ }^{30}$ This species-specific PCR helps in the rapid and accurate identification of $T$. asahii, which is the most frequently encountered pathogen among the Trichosporon sp.

Overall, T. asahii is the most common isolate 65 (90.3\%), compared to non-T. asahii 7 (9.7\%) in our study. This was consistent with the findings of few other studies where T. asahii was the predominant isolate. ${ }^{36,37}$

The fingerprinting analyses of the $65 \mathrm{~T}$. asahii strains using RAPD primer GAC-1, which produced 11 different patterns, demonstrated genetic diversity among the Trichosporon isolates in our study. However, there was limited diversity among T. asahii isolates using RAPD primer M13 that produced only five different patterns. A previous study by Ahmad et al, also demonstrated more genetic diversity among the $25 \mathrm{~T}$. asahii isolates by RAPD primer GAC-1, which yielded eight different patterns when compared to M13. ${ }^{30}$ The results of our study and the previous study indicate that RAPD analysis by GAC-1 may be more sensitive in determining minor changes in T. asahii genome. Genetically, diverse isolates of RAPD analysis may have arisen from prevalent genotype of the hospital environment by minor modifications, some of which could not be differentiated by M13 primer.

In our study, out of the 11 different patterns produced by RAPD typing using GAC-1 primer, pattern I (29.2\%) was the predominant one followed by pattern III (16.9\%). Patterns I and III were the predominant types from strains in South India and pattern $\mathrm{X}$ was the predominant one in the strains obtained from North India. Sugita et al were the first to describe five T. asahii genotypes, based on the diversity of the IGS1 sequences exhibited by T. asahii strains obtained from Japan, the United States, and Brazil. ${ }^{38}$ Rodriguez-Tudela et al also evaluated sequence polymorphisms of the IGS1 regions of $18 \mathrm{~T}$. asahii strains and recognized six different genotypes from patients in Argentina, Brazil, and Spain. The majority of them were representative of genotypes 1 and $5 .{ }^{39}$ Chagas-Neto et al analyzed the genotype distribution of $15 \mathrm{~T}$. asahii isolates obtained from blood samples from patients in Brazil and found that the majority of these strains belonged to genotype 1 (86.7\%). ${ }^{3}$ Kalkanci et al reported that from among 87 T. asahii clinical isolates from Turkey, as many as 69 strains (79.3\%) represented genotype 1 , followed by seven strains $(8.0 \%)$ representing genotype 5 , six strains (6.9\%) representing genotype 3 , three strains $(3.4 \%)$ representing genotype 6 , and only one strain $(1.1 \%)$ representing genotype $4 .^{19}$ Mekha et al studied $101 \mathrm{~T}$. asahii strains in Thailand and ascertained that genotype 1 (45 strains, 44.5\%) and genotype 3 (35 strains, 34.7\%) were the predominant types, followed by genotype 7 (18 strains, $17.8 \%$ ). ${ }^{40}$ Sellami et al identified four IGS1 sequence types among the $28 \mathrm{~T}$. asahii isolates that were studied, with majority of them being genotype 1 (46.4\%) and genotype 4 (35.7\%), followed by genotype 7 (14.3\%) and genotype 3 (3.6\%) in Sfax, Tunisia. ${ }^{37}$ A recent study by do Espírito Santo et al from Brazil identified 3 genotypes among the $12 \mathrm{~T}$. asahii isolates, genotype 1 (41.7\%), genotype 3 (33.3\%), and genotype 5 (25\%). ${ }^{32}$ A study by Rastogi et al in India on $20 \mathrm{~T}$. asahii isolates recognized genotype III as the most common type, followed by genotype I and VII. ${ }^{41}$ Hence, we can see the influence of different geographical locations in the prevalence and predominance of a particular genotype. Although genotyping Trichosporon strains by sequencing the IGS regions is the most discriminative method as described in previous studies, ${ }^{19,35,38}$ not all clinical laboratories have sequencing options for routine analysis. Genotyping of strains can be done by RAPD analysis in laboratories using PCR techniques.

Pattern I was found to be the predominant pattern among the $(34.2 \%)$ urine isolates and pattern $\mathrm{X}$ was the most predominant pattern among the blood (27.3\%) and PCN (57.1\%) isolates. Higher the correlation among the genotypes from a particular sample source, higher is the risk of exogenous nosocomial infection. Hence, typing of the strains can give informative data about the relatedness of the strains, especially if they are performed during an outbreak.

To conclude, molecular techniques enable rapid and reliable identification of $T$. asahii isolates at species level. Furthermore, this study reiterates the current outlook that T. asahii is the most common species associated with human clinical specimens and also has wide geographic distribution. Strain typing helps differentiate between the genotypes and reveals the correlation among them, establishing the relatedness of the strains, thus helping in outbreak investigation.

1. Source of financial Support: Nil (self-funded)

2. Details of early presentation: Nil

3. Ethics Clearance: Institutional Ethical clearance-REF: IEC-NI/12/MAR/27/14

\section{Conflict of Interest}

None.

\section{References}

1 Rastogi VL, Nirwan PS. Invasive trichosporonosis due to Trichosporon asahii in a non-immunocompromised host: a rare case report. Indian J Med Microbiol 2007;25(1):59-61

2 Colombo AL, Padovan ACB, Chaves GM. Current knowledge of Trichosporon spp. and Trichosporonosis. Clin Microbiol Rev 2011;24(4):682-700

3 Chagas-Neto TC, Chaves GM, Melo AS, Colombo AL. Bloodstream infections due to Trichosporon spp.: species distribution, Trichosporon asahii genotypes determined on the basis of ribosomal DNA intergenic spacer 1 sequencing, and antifungal susceptibility testing. J Clin Microbiol 2009;47(4):1074-1081

4 Suzuki K, Nakase K, Kyo T, et al. Fatal Trichosporon fungemia in patients with hematologic malignancies. Eur J Haematol 2010;84(5):441-447

5 Quindós G, Ruesga MT, Martín-Mazuelos E, et al. In-vitro activity of 5-fluorocytosine against 1,021 Spanish clinical isolates of Candida and other medically important yeasts. Rev Iberoam Micol 2004;21(2):63-69

6 Nagai H, Yamakami Y, Hashimoto A, Tokimatsu I, Nasu M. PCR detection of DNA specific for Trichosporon species in 
serum of patients with disseminated trichosporonosis. J Clin Microbiol 1999;37(3):694-699

7 Moretti-Branchini ML, Fukushima K, Schreiber AZ, et al. Tanaka, R.; Miyaji M. Trichosporon species in bone marrow transplanted patients. Diagn Microbiol Infect Dis 2001;39(3):161-164

8 Pfaller MA. Epidemiology of fungal infections: the promise of molecular typing. Clin Infect Dis 1995;20(6):1535-1539

9 Sugita T, Makimura K, Nishikawa A, Uchida K, Yamaguchi H, Shinoda T. Partial sequences of large subunit ribosomal DNA of a new yeast species, Trichosporon domesticum and related species. Microbiol Immunol 1997;41(7):571-573

10 Sugita T, Nishikawa A, Shinoda T. Rapid detection of species of the opportunistic yeast Trichosporon by PCR. J Clin Microbiol 1998;36(5):1458-1460

11 Sugita T, Nishikawa A. Molecular phylogenetic study of the basidiomycetous anamorphic yeast genus Trichosporon and related taxa based on small subunit ribosomal DNA sequences. Mycoscience 1998;39:7-13

12 Sugita T, Nishikawa A, Shinoda T. Identification of Trichosporon asahii by PCR based on sequences of the internal transcribed spacer regions. J Clin Microbiol 1998;36(9):2742-2744

13 Pagnocca FC, Legaspe MFC, Rodrigues A, et al. Yeasts isolated from a fungus-growing ant nest, including the description of Trichosporon chiarellii sp. nov., an anamorphic basidiomycetous yeast. Int J Syst Evol Microbiol 2010;60(Pt 6) :1454-1459

14 Fagundes Júnior AA, Carvalho RT, Focaccia R, et al. [Trichosporon asahii an emerging etiologic agent of fungal infection and colonization in heart failure patients in intensive care unit: case report and literature review]. Rev Bras Ter Intensiva 2008;20(1):106-109

15 Meyer MH, Letscher-Bru V, Waller J, Lutz P, Marcellin L, Herbrecht R. Chronic disseminated Trichosporon asahii infection in a leukemic child. Clin Infect Dis 2002;35(2):e22-e25

16 Sugita T, Nishikawa A, Ichikawa T, Ikeda R, Shinoda T. Isolation of Trichosporon asahii from environmental materials. Med Mycol 2000;38(1):27-30

17 Takamura S, Oono T, Kanzaki H, Arata J. Disseminated Trichosporonosis with Trichosporon asahii. Eur J Dermatol 1999;9(7):577-579

18 Toscano CM, Jarvis WR. Emerging issues in nosocomial fungal infections. Curr Infect Dis Rep 1999;1(4):347-361

19 Kalkanci A, Sugita T, Arikan S, et al. Molecular identification, genotyping, and drug susceptibility of the basidiomycetous yeast pathogen Trichosporon isolated from Turkish patients. Med Mycol 2010;48(1):141-146

20 Wolf DG, Falk R, Hacham M, et al. Multidrug-resistant Trichosporon asahii infection of nongranulocytopenic patients in three intensive care units. J Clin Microbiol 2001;39(12):4420-4425

21 Lo Passo C, Pernice I, Celeste A, Perdichizzi G, Todaro-Luck F. Transmission of Trichosporon asahii oesophagitis by a contaminated endoscope. Mycoses 2001;44(1-2):13-21

22 Sugita T, Ichikawa T, Matsukura M, et al. Genetic diversity and biochemical characteristics of Trichosporon asahii isolated from clinical specimens, houses of patients with summer-type-hypersensitivity pneumonitis, and environmental materials. J Clin Microbiol 2001;39(7):2405-2411

23 Carnovale S, Lorenzo J, Kaufman S, Finquelievich J, Guelfand L. Genotypic study of strains belonging to the genus Trichosporon. Med Mycol 2007;45(1):51-56

24 Lyman CA, Devi SJ, Nathanson J, Frasch CE, Pizzo PA, Walsh TJ. Detection and quantitation of the glucuronoxylomannan-like polysaccharide antigen from clinical and nonclinical isolates of
Trichosporon beigelii and implications for pathogenicity. J Clin Microbiol 1995;33(1):126-130

25 Magalhães AR, Mondino SS, Silva Md, Nishikawa MM. Morphological and biochemical characterization of the aetiological agents of white piedra. Mem Inst Oswaldo Cruz 2008;103(8):786-790

26 Mirhendi H, Makimura K, Khoramizadeh M, Yamaguchi H. A one-enzyme PCR-RFLP assay for identification of six medically important Candida species. Nippon Ishinkin Gakkai Zasshi 2006;47(3):225-229

27 Vijayakumar R, Giri S, Kindo AJ. Molecular species identification of Candida from blood samples of intensive care unit patients by polymerase chain reaction - restricted fragment length polymorphism. J Lab Physicians 2012;4(1):1-4

28 Premamalini T, Rajyoganandh SV, Vijayakumar R. Kindo AJ, Marak Rungmei SKM. Trichosporonosis - an association with clinical factors and its outcome. Int J Microbiol Res 2018;10(3):1078-1082

29 Altschul SF, Gish W, Miller W, Myers EW, Lipman DJ. Basic local alignment search tool. J Mol Biol 1990;215(3):403-410

30 Ahmad S, Al-Mahmeed M, Khan ZU. Characterization of Trichosporon species isolated from clinical specimens in Kuwait. J Med Microbiol 2005;54(Pt 7) :639-646

31 Ahmad S, Khan Z, Mustafa AS, Khan ZU. Epidemiology of Candida colonization in an intensive care unit of a teaching hospital in Kuwait. Med Mycol 2003;41(6):487-493

32 do Espírito Santo EPT, Monteiro RC, da Costa ARF, Marques-da-SilvaSH.Molecularidentification, genotyping,phenotyping, and antifungal susceptibilities of medically important Trichosporon, Apiotrichum, and Cutaneotrichosporon species. Mycopathologia 2020;185(2):307-317

33 Fujita SI, Senda Y, Nakaguchi S, Hashimoto T. Multiplex PCR using internal transcribed spacer 1 and 2 regions for rapid detection and identification of yeast strains. J Clin Microbiol 2001;39(10):3617-3622

34 Li HM, Du HT, Liu W, Wan Z, Li RY. Microbiological characteristics of medically important Trichosporon species. Mycopathologia 2005;160(3):217-225

35 Rodriguez-Tudela JL, Diaz-Guerra TM, Mellado E, et al. Susceptibility patterns and molecular identification of Trichosporon species. Antimicrob Agents Chemother 2005;49(10):4026-4034

36 Fleming RV, Walsh TJ, Anaissie EJ. Emerging and less common fungal pathogens. Infect Dis Clin North Am 2002;16(4):915-933, vi-vii

37 Sellami H, Trabelsi $\mathrm{H}$, Neji S, et al. First genotype identification of Trichosporon asahii in Sfax, Tunisia. J Med Microbiol 2017;66(4):397-401

38 Sugita T, Nakajima M, Ikeda R, Matsushima T, Shinoda T. Sequence analysis of the ribosomal DNA intergenic spacer 1 regions of Trichosporon species. J Clin Microbiol 2002;40(5):1826-1830

39 Rodriguez-Tudela JL, Gomez-Lopez A, Alastruey-Izquierdo A, et al. Genotype distribution of clinical isolates of Trichosporon asahii based on sequencing of intergenic spacer 1 . Diagn Microbiol Infect Dis. 2007;58:435-440

40 Mekha N, Sugita T, Ikeda R, et al. Genotyping and antifungal drug susceptibility of the pathogenic yeast Trichosporon asahii isolated from Thai patients. Mycopathologia 2010;169(1):67-70

41 Rastogi V, Honnavar P, Rudramurthy SM, Pamidi U, Ghosh A, Chakrabarti A. Molecular characterisation and antifungal susceptibility of clinical Trichosporon isolates in India. Mycoses 2016;59(8):528-534 